\title{
On the Actuality of the Tempo-Rhythms Research
}

\author{
Oleg N. Yanitsky", Ph.D \\ Professor, Chief Researcher, Federal Centre of Theoretical and Applied Sociology of the Russian Academy of \\ Sciences. Address: Krzhizhanovskogo Str., 24/35, bld. 5, 117218, Moscow, Russia
}

*Corresponding Author: Oleg N. Yanitsky, Professor, Chief Researcher, Federal Centre of Theoretical and Applied Sociology of the Russian Academy of Sciences. Address: Krzhizhanovskogo Str., 24/35, bld. 5, 117218, Moscow, Russia

\begin{abstract}
Space-time relationships are important characteristics of our living space including its natural, social and technical subsystems. Basing on the analysis of theoretical works of sociologists and anthropologists including some international research projects the author came to the following conclusions. First, each type of the mode of production has its own tempo-rhythm. Second, the cosmic space including the biosphere of our planet is featured by a variety of tempo-rhythms as their integral parts. Third, in the course of transition from one mode of production to another one their tempo-rhythms are sharply changed. Fourth, in the run of such shifts some societies are developing, others are stagnating, still others are degrading. Fifth, under conditions of the Fourth Scientific and Technological revolution (hereafter the STR-4) and the development of new information-communication systems our world-system is becoming a complex socio biotechical system (hereafter the SBT-system) with its own tempo-rhythm. Sixth, its space-time relationships require an interdisciplinary approach for an analysis of such complex systems. Seventh, a researcher of them should keep in mind that the SBT-system of various scale are not only interact with each other but generate a metabolic processes of mutual transformation. Eighth, in this respect the humanities have to learn to investigate such qualitative transformations. Ninth, the world megalopolises' space-time transformations present a challenge for joint efforts of interdisciplinary teams. Tenth, a careful study of an interregnum between the modernity and post modernity is needed. Eleventh, modern sociology should be more aimed at the rank-and-file needs and therefore humanistic-oriented.
\end{abstract}

Keywords: Biosphere, Globalization, Interdisciplinary Analysis, Interregnum, Megalopolises, Public Sociology, Space-Time Relationships, The SBT-Systems, Tempo-Rhythms.

\section{Some Methodological Premises}

First, our planet including its biological, social and technical components are dependent on cosmic sphere and, first of all, from the sun activity. This fact had been empirically confirmed by the investigations of two outstanding Russian researchers, V. Vernadsky (1980) and A. Chizhevsky (1924, 1976).

Second, today it is wrong to reduce a basing research paradigm to a society--nature interactions, as it has been done by the collective of research institute of Social Ecology in Vienna (Introduction, 2016: xli). Even more so that authors of the above Introduction see a labor as a central category of social ecology (ibid: li). The man-made technical or complex systems should be taken into account.

Third, a metabolism is not only an empirical approach to study of complex systemsbut a key methodological premise (Haberl et al., 2016).

Fourth, it follows that integrated SBT-systems of various scale have to be studied and conceptualized interdisciplinary (Yanitsky, 2016).

Fifth, the gap between tightly integrated material and virtual reality and disciplinary-divided science has to be overcome institutionally and mentally.

Sixth, in our mobile world any kind of sustainability may be only reached by permanent transformations, functional or structural ones.

Seventh, the postmodern world is uncertain and risky one. We often have no time for mitigation of such risks and therefore we are living in a society of 'side-effects' (Beck, 1999, 2007). 
Eighths, a space and time are important features of the life of all components of our living world, from macro to micro ones. Since our planet is the SBT-developing system, a researcher of any complex system has to take into account a 'time-table' of the mechanisms of their movement forward or, on the contrary, of their shrinking, decomposition and transformation.

Ninths, in sum the life of the planet as a whole as well as of its natural, social and technical components represents a myriad of different tempo-rhythms of their development, functioning and decay. The more these processes and structures are interdependent the more this integrated whole is needed in reconciling and coordination of its functions. But in any case an astronomic time is seen as stable while social one as mobile and dependent on the mode of social production and reproduction.

Tenths, when I'm speaking of the myriads of these tempo-rhythms it is not an exaggeration because every natural, technical or socially-constructed entity that joins these elements in a certain functioning whole has its particular rhythms of day-to-day functioning and evolution. Besides, one should keep in mind that such global organisms as the cosmos or the biosphere has their own tempo-rhythms of functioning which in turn define the tempo-rhythms of its parts, from macro (for example, a nationstate) to microstructures ranging from the individuals and their small groups till microns and other elementary particles of the world.

Eleventh, as concerns methods and instruments for the study of space-time relationships, I think that public opinion surveys are not fit to post-modernity condition because the speed of such surveys is incomparable with the speed and oscillations of current space-time relationships. Then, in the individualized society a variety of particular situations in situ is not fit to generalized methods of aggregation of opinion survey results. Therefore, in all critical and in a majority of mobilization situations to conduct public opinion surveys are practically impossible. After then, methodologically wrong to artificially separate information-communication processes from material ones. Thus, the information which is needed for the taming of political and social processes has to come in uninterrupted regime that could be studied by constant monitoring only.

\subsection{From Modernity to Post-Modernity}

The modern STR-4 not only permanently speeding up a 'run of the time' but provokes deep changes in overall institutional structure of the world. This acceleration forces the transformation of a relatively stable global social order established after the WWII into many competing and contradictory time-space relations across the globe. Therefore, this international global order has been gradually undermined by endless chains of bargaining, talks, road maps construction and other timespace relations 'in situ.' On the individual's and local community's levels the time-space relations remains relatively stable while on regional and global levels they experienced permanent transformations. Theoretically, it means that an astronomic (a celestial mechanic) time dominated in previous epochs has been replaced by socially-producing ones. And the relationships between the two shifted in favor of the latter ones.

Another principled turn has been marked by the shift in the leadership in social time production. On the previous phase of mode of production a science coupled with technological inventions has been the leader. Recently not the science as an institution but global stakeholders coupled with media magnates and political leaders of global scale are shaping the global political agenda and the temporhythms of decision-making processes. Any delay or drop out from these processes means not only a weakening of a political stand at the global political arena but a total drop out from the shaping of global political processes and rules.

An impact of the STR-4 on an individual's behavior varied for different social groups of rural and urban residents. Nevertheless, there are some features in common. The overwhelming majority of them are forced to follow the speeding up and compression of social time produced by the STR-4. The permanent social time acceleration coupled with a media pressure and a growing uncertainty of overall global situation only aggravates the risk of the loss of an individual stability of existence. A reality is breaking down into an endless kaleidoscope of chaotic events.

Another definite negative effect produced by the STR-4 is a growing speed of transportation of individuals. A passenger is only fixed on two points, a starting and destination (terminal) ones. All other events, be it the landscapes or national peculiarities are effaced, i.e. evaporated from an individual's memory and it is becoming poor and flat. A diversity and continuity of global nature, 
human history and culture is breaking and therefore shrinking into a set of business or relaxation points. In sum, a growing speed of spatial mobility leads to an alienation of individual fromhis/her living environment.

Z. Bauman in his last book posed two key questions related to the period of transition from modernity to post-modernity in which we are now. It is going on the relationships between global and local agencies and between modern and postmodern modes of governance. 'During most of the modern era, managerial strategies...were focused on rendering behavior of their subordinates utterly predetermined and therefore predictable though eliminating or suppressing all and any factors of influence other that the commands issued by the superiors; those strategies involved as their major tenet the repression by the subordinates of their personal idiosyncrasies...for the duration of performing the tasks set by their superiors...'. The quality of performance was measured and judged down to the single yardstick 'of the job having been done as commanded' (Bauman, 2017: 114-115).

In the times of hard modernity, Bauman continues, 'the managers used to record individual idiosyncrasies of the managed on the side of liabilities.' The managers repressed 'those liabilities and better still to extirpate them altogether, as factors throwing out of balance routine and uniformity, the two pillars of an instrumentally-rational performance and also of a smooth and unswerving goalpursuit' (Bauman, 2017: 115).

According to him, the liquid phase of modernity means a new management strategy. It has been characterized by 'the shifting of responsibility for the results $<$ of production $>$ onto the shoulders of the managed, simultaneously reducing the responsibilities of the managers according to the promise of profitability they hold for the enterprise and to the evaluation of quality (measured first and foremost in financial terms) of what they deliver.' As Bauman stated, it means 'the thorough and well-nigh comprehensive individualization of the employer-employee relations' (Bauman, 2017: 116).In that and other books Bauman posed two of the key questions related to the period of transition from modernity to post-modernity. It is going on the relationships between global and local agencies and between modern and postmodern modes of governance and management.

'During most of the modern era, managerial strategies... were focused on rendering behavior of their subordinates utterly predetermined and therefore predictable though eliminating or suppressing all and any factors of influence other that the commands issued by the superiors; those strategies involved as their major tenet the repression by the subordinates of their personal idiosyncrasies...for the duration of performing the tasks set by their superiors...' The kind of performance was measured and judged down to the single yardstick 'of the job having been done as commanded." In the times of hard (solid) modernity 'the managers used to record individual idiosyncrasies of the managed on the side of liabilities.' The managers repressed 'those liabilities and better still to extirpate them altogether, as factors throwing out of balance routine and uniformity, the two pillars of an instrumentally-rational performance, and also of a smooth and unswerving goal-pursuit' (Bauman, 2017: 114-115).

According to Bauman, the liquid phase of modernity is characterized by new managerial strategy. Any side-effects of it has been shifting of responsibility for the results onto the shoulders of the managed, simultaneously reducing the responsibilities of the managers according to the promise of profitability they hold for the enterprise and to the evaluation of quality (measured first and foremost in financial terms) of what they deliver. As Bauman stressed, it means the all-embracing and comprehensive individualization of the employer-employee relations.

\subsection{An Interregnum Problem}

In the period of transition from one mode of production and mode of living to new one the significance of the tempo-rhythms of transition is sharply growing. Bauman called this issue as $a$ problem of an interregnum or a 'state in-between' in such systems in transition. 'Interregnum - the condition in which the old ways and means of getting things done have stopped already working properly, yet the new, more effective ways and means are still at the designing stage or at best in the stage of experimentation - has its temporal, to wit 'diachronic', but also its spatial, that is 'synchronic' dimension. Calling our present condition an 'interregnum' we refer to a time-span of yet unknown length, stretching between a social setting which has its course and another, as yet underdefined and most certainly under-determined, which we expect or suspect to replace it.' (Bauman, 2017: 119). I'd draw the reader's attention to the fact that the very interregnum is also not permanent but is dependent on the development of means of information and communication i.e. on a speed of 
inversion of a space into time. So, to my mind, it is more correct to speak not only about a time of transition from one state of a particular complex system to another, but about of a tempo-rhythm of a given interregnum.

Bauman was absolutely right speaking in this connection about the changing morphology of human togetherness or the structure of human co-habitation. 'Old structures... are falling apart, its fragments enter new and untested arrangements emergent settings are spattered with blank spots and ill-fitting fragments in an advanced stage of despair, as well as with other zombie-like fragments, still mobile though out of joint and lacking obvious uses and applications: the condition typical of "failing systems' (Bauman, 2017: 119).

All in all, it means that the postmodern epoch is the time of permanent re-composition of large complex systems, and it is one of their peculiarities as unstable and therefore uncertain and potentially risky ones. 'The structures once interlocked into something reminiscent of a system are now, clearly, in disarray. But structures' function is to serve as catapults as well as guiding/steering frames for action.' It is the 'big, perhaps the biggest question of the time of interregnum, fully and truly the 'meta-question' - one that needs to be answered in order to for all the rest questions' of our transition era(Bauman, 2017: 120).

\section{AN IMPORTANCE OF A STUDY OF THE TIME AND TEMPO-RHYTHMS OF MODERN MEGALOPOLISES}

Actually, all phenomena of urban life are of material origin. And all urban metabolic processes of various character and scale have information nature. Here I offer to distinguish material and virtual phenomena of urban life, especially on its middle level and micro ones. From the information viewpoint, there are no territorial barriers or boundaries at all. Although, every urban dweller has its own living space, be it local, regional or global. Such particular areas are called by the sociopsychologists as a mastered area defined by a personal or group as a 'dynamic stereotype' (Abul'khanova-Slavskaya, 1980).

For urban aborigines such stereotypes as a rule have a long life, sometimes several years. It means that they are the microstructures that maintain a relative sustainability on the abovementioned levels and therefore represent a socio-temporal element of a mega-city structural-functional organization. The migrants and other newcomers have entirely another 'dynamic stereotype.' Its essence is permanent commuting between temporary workplace and a permanent place of residence.

At the same time, the megalopolis as a territorial integrity is a very complicated system and therefore a 'cluster of different times' (Sassen, 2000).Its complexity is conditioned by a concentration of various human activities, functioning of different infrastructures, by the tempo-rhythms of activity of natural and man-mad ecosystems. It has to be underscored that a particular megalopolis (as the SBTsystem) has its own time of functioning and dynamics. Don't forget about numerous logistics that have their own tempo-rhythms. Finally, it is clear that this concert of various times and rhythms is dependent on to which class of networks - global, national or local - it belongs.

Roughly speaking, there are three main archetypes of the mega-cities functioning: 'normal', mobilisational and critical ones (here I don't consider the case of total decay of a megalopolis). But all the above archetypes have one more type of time being. The matter is that every archetype has not only a certain tempo-rhythm of functioning but the time of emanation of energy of decay. Some of megalopolises continue to develop, others remain relatively stable and still others collapsed - it is a law of every complex system.

Then, an actual flow of time and its subjective perception and experience is dependent on a system of the coordinates in which an individual or a group used to live. If he/she is oriented on the past it is one thing, on the present -another one, if on the future - a third one. But as Russian social-psychologist Igor Kon noted, a man usually fulfilled many roles simultaneously but never identified himself with them. That is why I've stated that at the 'bottom' level urban environment is rather mobile and the mode of such mobility is conditioned by the fact to which particular archetype a given megalopolis belongs.

The above typology of residents' behavior doesn't mean that the norm of his/her way of life is a kind of relaxation only. On the contrary, the norm of human life in the megalopolises usually has a mobilization character. An individual's life is under permanent pressure of social, economic, cultural and other forces i.e. his/her life is under permanent tension. This tension may be partly removed by the contacts with nature and with relatives and friends (www.ecotherapy.ru). 


\section{Time CharaCteristics of THE InSTITUTE OF KNOWLEdGe ProduCtion AND DisSEMination}

As it has been noted by many researches of this institution, it is much more complicated as it may appear at the first glance (Irwin and Wynne, 1996; Irwin, 2001; Latour, 1987, 1998). As many other social institutions, the science is not only gradually evolving but has its turning points. Roughly speaking, the current evolution is marked by the turn from mechanical worldview towards technocratic and biological ones.

Then, as B. Latour(1998) pointed out two decades ago modern science is in the transition from the world ofscience to the world of research. And I'd like to add the shift to the world of international comparative research. The long-term global risk researchand a socio-ecological research across time and space are the best examples of this stream (Haberl at al., 2016; Global Risks..., 2016).

After then, a new direction of knowledge production has emerged. One line is a science-public relationship. As many modern researchers and public figures argues, in the age of the internet and world-embracing mass-media a scientific knowledge cannot exists and influence social life without it its presence in the mass-media. They argued that science cannot survive without being accepted by media because in the final analysis it means the acceptance of media magnates. As A. Arsenalt and M. Castells clearly showed (2008) such dependence means a possibility of manipulation of public consciousness by only two simple operations, by switching media channels or/and reprogramming their content.

The second line is a collaboration of the scientists and other academics with the grassroots, social movements and active individuals. The line of knowledge production is divides into two streams. One which I conditionally call the 'top-down' consists of scientists and other academics that gradually turned into environmental and other public activists (Yanitsky, 2005).The other represents a back, 'bottom-up' movement of social and political knowledge. This kind of knowledge-based political and practical skills is produced by young people graduated from the universities. This kind of multidisciplinary and politically-sound knowledge is created by the graduated that are capable to join local knowledge with universal one and who are not afraid to be in the midst of conflicting situations, never mind be it local, regional or global. They interpret a 'region' not in an administrative but in geopolitical or environmental terms (Simonov and Egidarev, 2017).From my view point, this kind of participatory observation coupled with local and global knowledge is the most efficient way to get practical political and public results. Of course, such knowledges have to be permanently renovated by means of multisided monitoring.

A time is not only means money, as the proverb says. The time is a multisided resource of natural and social life. An astronomic as well as the biological, social and technical times is different but mutually interdependent. Our world is constructed from the myriad of qualitatively different structures and processes. They are emerging, developing, maturing and declining and it is a non-stop process. All of them are interacting with each other and each of them has their own tempo-rhythm regime. Such regimes may have a linear or a cyclic character generating twists and unintended consequences from time to time.

Then, some of the above processes are of natural origin while the others are socially designed and then technically constructed. It means that the tempo-rhythms of their functioning are sociallyconstructed as well. After then, a socially or politically-constructed facts, knowledges, developments or political decisions and their implementation have their own tempo-rhythms that may be different at local, middle or global level.

At the individual's level the gap between the astronomic and social times is growing. The former are usually remains stable while the latter is compressed more and more every minute.

\section{A HiSTORICAL OVERVIEW ON THE ISSUE OF TEMPO-RHYTHMS DYNAMICS}

In the remote past of humanity the tempo-rhythms of the humans had been totally subjected to the dynamics of the outer space and by the biosphere, in particular. All forms of human activity had been regulated and guided by natural processes including the cosmic ones. But even in those times humans had been not only subjected to that processes but had learned by them.

With the emergence of ancient human communities and their activity aimed at their survival the 'time factor' gradually acquired an increasing role in their life and survival. The emergence of humans' 
comprehension of space-time dimensions of their life and well-being, of getting to know the laws of celestial and earth mechanics gradually shaped a 'mechanical view' on human life. At the same time a philosophy began to shape its own view on social mechanics.

The impulse to such comprehension gave an emerging mastering of the globe by humans (travelers and conquistadors) and exchange processes. It seems to me that two instruments of such mastering took a leading role: a trade and the wars. K. Marx was right stating that a labor created a man and humanity as a whole. It is the labor was a main instrument by which a man step by step mastered the world.

An expanding human practice was needed in theoretical comprehension and this gave new stimuli to the farther mastering of the world. It had been double-sided but united process. The other side of it was a necessity to coordinate and to reconcile natural, social and technical processes. Sooner or later, a logistics as an instrument of such coordination has to be emerged. The logistics is an applied interdisciplinary knowledge and practical instrument.

The development of human settlements signified two shifts in the phenomena of our interest. These settlements as such created their own tempo-rhythms different from that of natural ecosystems. At the same time these settlements began to impose their tempo-rhythms on surrounding villages and natural landscapes.

An industrial revolution of XVII-XIX centuries meant a growing domination of mechanic view over all other natural and human ecosystems around the world. A tandem of natural sciences and industrial technologies had been shaped. With each 'round' of industrialization of the world the role of production networks and human communications between spatially separated elements of production processes has been growing. Various forms of the logistics came to the forefront.

In time, in the transition from an industrial revolution to post-industrial one the time-space relationships have changed again. By and large socially-constructed forms of industrial production and dissemination of its 'good and bad' (U. Beck) end-products began to dominate over natural processes and their tempo-rhythms. I call this shift as post-industrial 'time revolution.' The matter is in the emergence of inversion of space into time phenomenon. But it is a rather tricky phenomenon. On the one hand, it allowed to a particular human communities and global stakeholders to take over on their competitors and adversaries. On the other hand, these races lead these competitors to the conflicts with natural tempo-rhythms. So that the 'time revolution' of post-modern epoch is Januslike.

These principled transformations have been analyzed long ago, by McLuhan (1964) whose position corresponded in general with Durkheim's division of our history in two epochs, mechanical and organic solidarities. I prefer to speak not in terms of different solidarities but in terms of different means of technologies of production and communication. M. Waters, referring to McLuhan, wrote that two important shifts have occurred. 'First, the mechanical clock disrupted recursive and seasonal conceptions of time and replaced them by a durational conception where time is measured in precise divisions...The second device is money (Giddens' 'symbolic tokens') which increases the speed and volume of relationships' (Waters, 1995: 34).

In post modern epoch 'the predominant industrial and individualizing media of print, the clock and money are being displaced by electronic media...Its key characteristic is speed...Linear sequencing and thus rationality are dispatched by electronic speed-up and the synchronization of information the world is experienced not simply globally but chaotically' (Waters, 1995: 35). Finally, the accelerating effects of electronic communication and rapid transportation create a structural effect that McLuhan calls 'implosion.'... It means that the 'center-margin structure of industrial civilization disappears in the face of synchrony, simultaneity and instantaneousness' (Waters, 1995: 35).

If simultaneity of human activity is really exists it is not well understandable how the 'liberation of time and space' (or time from space, or their dis-embedding) is possible under conditions of allembracing inequality and tough struggle between global, regional and local stakeholders? To my mind, on the contrary there is a strong interdependence between the time of functioning of global stakeholders and their adversaries. The adherents of the 'dis-embedding' of time from space are forgetting that tempo-rhythms of a particular social agent (local community or corporation) are totally dependent on technological, financial and geopolitical resources now at hands. And my adversarial 
position is confirmed by the statement as following: 'Modernity therefore involves both high trust and high risk' (Waters, 1995: 49).

D. Harvey (1989: 241) stated that postmodernity produces a phenomenon of time-space compression, a development in which time can be reorganized in such a way as to reduce the constraints of space and vice versa. This compression is not smooth because it is a result of a permanent struggle for new resources and geopolitical domination. A typical case is the situation of any form of social and geopolitical conflict or/and a result of any critical situation (from natural or man-made disaster till global hybrid war). But even in the 'normal' i.e. more or less peaceful times various forms of compression are permanently generated by very essence of competing nature of modern capitalism. More than that, a transition from productive capitalist system to consumer-oriented one always enhances this competition.

\section{TEMPO-RhythMs OF A PRIMARY ECO-STRUCTURE}

I've introduced this concept in mid-1980s using the results of international comparative project on public's participation in shaping the urban environment (Deelstra and Yanitsky, 1990) and refined it in the beginning of the 2000s (Yanitsky, 2012). This structure is a human microcosm in which all necessary resources are at hands and in which he or she or the family may feel themselves in a relative safety. Of course, it's a model i.e. 'normal' case because a mobilization or critical situation he/she/they feel themselves quite another.

Usually, this eco-structure has three balanced time dimensions: the past, the present and the future. It's again a model case that more or less fits to the era of modernity in which the relationships between a person and his/her social and natural environment has been relatively stable in foreseeable future. Transformations or innovations happened from time to time but the above triple time-balanced construction remains stable. The tempo-rhythms of transmission of handicraft and knowledge from the elderly to the young were not seriously changed in the frames of one or even two generations.

In postmodern era (I prefer to define it as the STR-4) this primary eco-structure has dramatically changed. The past lost its significance as a guide for an individual of family life-story. The present has become uncertain and rapidly changing. In one way or another, an individual has become confronted with hardly predictable and quickly changing future. Then, as J. Urry (2008) rightly pointed out in our age of total mobility there is no room for any stable (and, to my mind, sustainable) nuclei for longterm well-being.

In such rapidly changing and uncertain situation an individual risks to lose his/her identity and to be transformed into eternal commuter or stranger. It means that he or she lost a feeling of their small Motherland, that they are becoming totally uprooted. Their contacts have become sporadic and not sustainable as well. In the end their way of life acquires a galloping character; human ties are breaking; and a state of alienation is coming.

\section{Where is A Place For PUblic Sociology?}

I'm convinced that being at the crossroads of the above variety of time-space relations the sociology should be a public one. It doesn't mean that it should be only public. It means that in so complex and diversified world the sociology cannot restrict itself by a particular issue or a sphere of social life. Modern world has become multisided, inter depended and mobile and the sociology has to meet these challenges. To my mind, the very term 'public' signifies a necessity to serve to humanity, never mind be it a small group, community or a nation-state. For further researches (not just mine) I offer to rely upon a set of ideas laid down by M. Burawoy.

First, the aspiration of public sociology is stronger and realization ever more difficult, as sociology has moved left and the world has moved right. Second, there are multiple public sociologies. Tradition and organic public sociologies are two polar but complementary types. Third, public sociology includes policy sociology, professional sociology and critical sociology. Fourth, the question 'for whom' and question 'for what' define the fundamental character of a particular branch of this discipline.

Fifth, usually the sociologist occupies multiple of disciplinary locations, and this fact signifies his/her interdisciplinary potential. Sixth, the development of sociology depends upon a shared ethos, underpinning the reciprocal interdependence of three abovementioned mainstreams of sociology. 
Seventh, each of them is a field of power. In practice an instrumental sociology prevails on reflexive one. Eighth, being institutionally-sound professional sociology usually dominates but public sociology is often more important. Ninth, the social sciences are at the crossroads of the humanities and the natural sciences, therefore they are potentially interdisciplinary ones. A cross-disciplinary borrowing and multi-disciplinary collaboration are the facts of our times. Tenth, in the times of market tyranny and state despotism the public sociology defenses the humanity. Eleventh, the standpoint of sociology is civil society and the defense of social (Burawoy, 2005).

\section{CONCLUSION}

The space-time relationships in the past and the present of human civilization and its interaction with the biosphere are still not investigated enough. Meanwhile, every mode of production including the processes of reproduction of the societies and human relationships has their ownspecific temporhythms. A division on true agents and their environment is rather conditional because if a carrying capacity of a particular environment is exceeded, a 'passive' environment is transforming into agents and vise versa.

The most acute issue of time-space relationships is a period of the interregnum between the modern and post-modern. In the run of it all agents and the environments of the global SBT-system and its integral parts experience substantial transformations. We are now in the midst of such 'in-between' period. Even in such economically and technologically advanced countries as the US one could observe contradictory trends. It signifies that for the comprehension of the regularities of this period to learn the advances in the IT-technologies is insufficient - deep sociocultural and biophysical investigations are needed.

It is important that various participatory programs assist to bridge an academic knowledge, fieldresearch knowledge with knowledge produced by local social and environmental initiatives. Such programs allow to draw indigenous people in transnational research and public activity (Ilcan and Phillips, 2008).

Directive (top-down) regulation of complex processes and (bottom-up) self-regulated entities have different tempo-rhythms. A permanent emergence of local initiatives, groups of interests and lobbyists diversified an urban milieu and therefore withstand to the all-levelling intentions of the transnationals.

As to advances in the development and application of interdisciplinary analysis, it seems to me that the anthropologists are in the most winning position because they analyses local SBT-systems as inseparable integrities. Only an interdisciplinary analysis may catch such invisible phenomena as time-space compression. On the contrary, the public opinion surveys are not fit to a speeding up development or degradation of existing SBT-systems. To my mind, their studies should be based on their permanent monitoring and then treated and analyzed by the teams of so-called 'full-time integrators.'

In many parts of the world the interdisciplinary teams are shaping including the specialists in social and cultural anthropology. It is indicative that the leaders of such teams have become not only true multi-disciplinary professionals but they become experienced people capable to communicate with various strata of tribal, developmental and advanced representatives. It has become possible as a result of growing number of well-educated young graduates from the universities who couldn't apply the acquired academic knowledge and would like to combine it with local knowledge and skills.

Sociology should be more civil-society-oriented including thorough analysis of the microcosms' tempo-rhythms. Public sociology is a sociology aimed at meeting the interests and needs of particular groups of rank-and-file people. That is public sociology has to be simultaneously humanistic and environmentally-oriented.

\section{REFERENCES}

[1] Abulkhanova-SlavskayaK. 1980. An activity and the psychology of a personality. Moscow: Nauka Publishing House (in Russ.).

[2] Arsenault A. and Castells M. 2008.Switching Power: Rupert Murdoch and the Global Business of Media Politics. International Sociology 23(4): 488-513.

[3] BaumanZ. 2017. A Chronicle of Crisis: 2011-2016, with the preface by Dr. N. Lawson. London, UK: Social Europe Edition 2017. ISBN 978-1-9997151-0-6

[4] Beck U. 1999.World Risk Society. Malden, MA: Polity Press. 
[5] Beck U. 2007.Cosmopolitan Version. Cambridge: Polity Press.

[6] Burawoy M. 2005. For public sociology.American Sociological Review, Vol. 70: 4-28.

[7] Chizhevsky A.L. 1924. Fizicheskiefaktoryistoricheskogoprocessa [Phisycal Factors of a Historical Process]. Kaluga: PervayaTipolitigraphiya.

[8] Chizhevsky A.L. 1976. Zemnoeehosolnechnykh bur' [The Earth Echo of Sun Storms]. Moskva: Mysl'.

[9] Deelstra T. and Yanitsky O., eds. 1991.Cities of Europe: The Public's Role in Shaping the Urban Environment. Moscow: MezhdunarudnyeOtnosheniya.

[10] Funtowicz S. and Ravetz J. 1999. Post-normal Science: An Insight now Maturing. Futures 31: 641 -646.

[11] The Global Risks Report 2016. Geneva: World Economic Forum. Available at: www.weforum.org/risks

[12] Haberl H., Fisher-Kowalski M., Krausmann F. and Winiwater V., eds. (2016).Society-Nature Relations across Time and Space. ISBN (on-line): 978-3-319-33326-7. Available at: http://link.springer.com/book/ $10.1007 \% 2$ F978-3-319-33326-7

[13] Haberl H. et al. 2016. Introduction, in: Haberl H., Fisher-Kowalski M., Krausmann F. and Winiwater V., eds. Society-Nature Relations across Time and Space: li.

[14] Gregory, J. and Miller, S. 1998. Science in Public. Communication, Culture and Credibility. Cambridge, MA: Basic books.

[15] Ilcan S. and Phillips L. 2008. Governing trough global networks. Current Sociology, 56(5): 711-734.

[16] Irwin A. 2001. Sociology and Environment. A Critical Introduction to Society, Nature and Knowledge. Malden, MA: Polity.

[17] Irwin A. and Wynne B., eds. 1996.Misunderstanding Science? The Public Reconstruction of Science and Technology. Cambridge: Cambridge University Press.

[18] Latour B.1987.Science in Action. Cambridge: Harvard Univ. Press.

[19] Latour B. 1998. From the World of Science to the World of Research? Science, 280: 208-209.

[20] Ringhofer L. and Fisher-Kowalski M.2016.Method Precis: Functional Time Use Analysis, in: Haberl H., Fisher-Kowalski M., Krausmann F. and Winiwater V., eds. (2016). Society-Nature Relations across Time and Space, p. 5195-522.

[21] Sassen S. 2000. Territory and Territoriality in the Global Economy, International Sociology, Vol. 15 (2): $372-393$.

[22] Simonov E. and Egidarev E. 2017. Intergovernmental cooperation on the Amur riverbasin management in the twenty-first century. International Journal of Water Resources Development.DOI: 10.1080/07900627. 2017. 1344122

[23] Robertson R. 1994. Globalization. Social Theory and Global Culture. London: SAGE Publications.

[24] Schwab K.2016The Fourth Industrial Revolution. Geneva: World Economic Forum.

[25] Smetska B., GaubeV. and Lutz J. 2016. Time use, Gender and Sustainable Agriculture in Austria, in: Haberl H., Fisher-Kowalski M., Krausmann F. and Winiwater V., eds. 2016. Society-Nature Relations across Time and Space, p.505-518.

[26] Urry J. 2008.Mobilities. Cambridge: Polity Press.

[27] VernadskyV. 1980.Problems of a Geochemistry. Works of the Biogeochemical laboratory. Vol XVI. Moscow: Nauka (in Russ.).

[28] YanitskyO. 1996. TheEcological Movement in Post-Totalitarian Russia: Some Conceptual Issues, Society and Natural Resources, 9, pp. 65-76.

[29] Yanitsky O. 2005. Dialogue between Science and Society.Social Sciences. A Quarterly Journal of the Russian Acad. of Sciences Vol. 36 (2): 78-90.

[30] Yanitsky, O. 2012. A Primary Eco-Structure: The Concept and its Testing. Social Analysis, Vol.2 (2): 7-24.

[31] Yanitsky O. 2016.Sotsiobiotechnical systems: A new Approach to Man-Nature Interactions, in: On Globalization and its Environmental Consequences. The Yanitsky Reader II Available at: http://www.isras.ru/ index.php? page_id=1198\&id=4603 pp. 123-135.

Citation: Oleg N. Yanitsky. " On the Actuality of the Tempo-Rhythms Research" International Journal of Research in Sociology and Anthropology (IJRSA), vol 4, no. 2, 2018, pp. 31-39. doi: http://dx.doi.org/10.20431/2454-8677.0402004.

Copyright: (C) 2018 Authors. This is an open-access article distributed under the terms of the Creative Commons Attribution License, which permits unrestricted use, distribution, and reproduction in any medium, provided the original author and source are credited. 